\title{
Examining the Relationship Between Criminogenic Thinking, Differential Identification, Motivation, and Risk-Taking Behavior in Emerging Adults
}

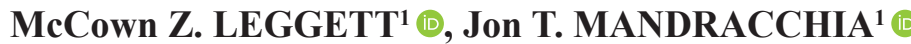

${ }^{1}$ Missouri Western State University, Department of Psychology, Missouri, USA

ORCID: M.Z.L. 0000-0002-2909-9484; J.T.M. 0000-0003-4108-4127

\section{ABSTRACT}

Young adults engage in a disproportionately high rate of problematic behaviors such as risky sexual activities, academic dishonesty, and substance abuse. In order to understand why this occurs, two lesser-known constructs related to risktaking behavior were investigated in this study: differential identification, which has yet to be empirically studied in the context of emerging adults, and criminogenic thinking, which has only been evaluated in this context to a minimal degree. To bridge the gap between these two constructs, motivation was hypothesized to be a moderator in each of these respective relationships. Data from 309 emerging adults were recruited via Amazon's Mechanical Turk (MTurk) to complete the survey materials online. The analysis consisted of a hierarchical multiple linear regression. Results indicated that motivation did not moderate either relationship (i.e., differential identification and risk-taking behavior and criminogenic thinking and risk-taking behavior). However, a main effect was found between one aspect of differential identification and risk-taking behavior. No other main effects were found in this study. Potential explanations for the results of this study are discussed, as well as implications and directions for future research.

Keywords: Criminogenic thinking, differential identification, risk-taking

Submitted: 14.09.2020 • Revision Requested: 30.10 .2020 • Last Revision Received: 14.11 .2020 • Accepted: 07.12 .2020 Published Online: 08.01.2021

Corresponding author: McCown Z. Leggett, E-mail: McCown.Leggett@ttu.edu

Citation: Leggett, M.C.Z., \& Mandracchia, J.T. 'Examining the Relationship Between Criminogenic Thinking, Differentia Identification, Motivation, and Risk-Taking Behavior in Emerging Adults' (2020) 8(2) Ceza Hukuku ve Kriminoloji Dergisi-Journal of Penal Law and Criminology, 275. https://doi.org/10.26650/JPLC2020-0026 


\section{Introduction}

The transition between adolescence and adulthood is often a pivotal moment in a person's life. Known as emerging adulthood, this developmental life stage is characterized by an increase in self-exploration and autonomy (Arnett, 2000). During this time period, changes are occurring in nearly every aspect of life-relationships, finances, cognitive development, etc. While this can lead to growth and many positive experiences, certain problematic behaviors are significantly more prevalent in emerging adults than any other age group. For instance, according to the Centers for Disease Control and Prevention (CDC, 2017), nearly half of the approximate 20 million sexually transmitted infections (STIs) each year are contracted by individuals 15-24 years old. Another sex-related issue for emerging adults is unintended pregnancy, where the highest rates are among women ages 18-29 (Finer \& Zolna, 2016).

Another risky behavior in which emerging adults actively engage in is alcohol use. According to the Substance Abuse and Mental Health Services Administration (SAMHSA, 2018), nearly four out of 10 emerging adults binge used alcohol in 2017. Relatedly, nearly 30 percent of impaired drivers in 2017 were between 21 and 24 years of age (National Highway Traffic Safety Administration, 2018). Within this same realm is illicit drug use, in which approximately one-fourth of young adults are currently involved - the highest proportion among any age group (SAMHSA, 2018). In a single calendar year (2015-2016), there was a $28 \%$ increase in drug-related deaths in individuals 15-24 years old (Hedegaard, Warner, \& Miniño, 2017). According to the Gateway Foundation (n.d.), drug abuse results in the most illnesses, disabilities, and deaths compared to other preventable health conditions.

Yet another risky behavior that is disproportionately experienced by emerging adults is partner dating violence. For example, in one study approximately $40 \%$ of participants had experienced physical or sexual victimization by the time they reached young adulthood (Halpern et al., 2009). Aggressive behavior, in general, tends to be engaged in more commonly by emerging adults, with males more frequently displaying verbal and physical aggression and females more frequently displaying relational, nonverbal, and verbal aggression (Nelson et al., 2008). Reckless driving is another risky behavior that is disproportionately engaged in by emerging adults, with individuals in the 16-24 age group having particularly high risk of crashing (Arnett, 2002). One reason for this is texting, as one study found that emerging adults texted on average $40.2 \%$ of days while driving (Trivedi et al., 2017). Academic dishonesty is yet another problematic behavior 
in which young people frequently engage in. According to a series of studies conducted by McCabe and the International Center for Academic Integrity (2015), approximately $68 \%$ of undergraduate students and $43 \%$ of graduate students admit to cheating on assignments or tests. Besides undermining the work and integrity of non-cheating students, cheating can carry on into future problematic behavior. For instance, Hooper, Komarraju, Weston, and Dollinger (2007) found that college students who plagiarized perceived themselves as more likely to participate in rule-breaking behavior as adults.

Beyond considering the prevalence and outcomes of engaging in risky behavior, a large amount of research has been conducted to learn why individuals choose to engage in risky behavior. For the purposes of this study, two lesser known constructs were investigated. The first construct, which has largely been ignored in the literature, is differential identification. Developed by Glaser (1956), differential identification is an extension of Sutherland's differential association theory, focusing on both real and imaginary people who can be either inside or outside of an individual's social circle. Unlike differential association, which theorizes that individuals learn deviant behaviors from deviant individuals whom they frequently associate with (i.e., mere exposure), differential identification theorizes that individuals engage in deviant behaviors because they identify with deviant individuals. Glaser (1956) argued that not all individuals identify with the people they are surrounded by and will instead seek out another person or group to identify with, and that these may even be people or groups with whom there is no direct interaction (e.g., celebrities, fictional characters). For example, while an individual who grows up in a law-abiding environment (e.g., with law-abiding parents, peers, etc.) associates with law-abiding individuals, he or she may reject their teachings and choose to identify with rule-violating individuals instead. To clarify further, the fundamental difference between differential association and differential identification is that differential identification involves actively identifying with a real or imaginary person. With differential association, although an individual may spend a significant amount of time with someone, they may not necessarily identify with them. Additionally, differential association only involves real individuals, whereas differential identification also includes imaginary or fictitious individuals.

Stratton (1967) studied differential identification in the context of reference groups within prison inmates and found an association between criminal identification and attitudes towards breaking the law. The only other study found referencing differential identification was by Stack (1990), which examined whether suicide stories of divorced 
and unhappy couples in the media resulted in higher suicide rates among actual divorced and unhappy couples. A significant association was found between the two, which was attributed to differential identification- however, it was never explicitly measured in the study. Although it seems as though little research has been dedicated to studying differential identification, the more general concept of identification has been studied in depth. With the ever-growing impact of social media, there is an even greater opportunity for young adults today to feel closer to those outside of their immediate circle, which can have both positive and negative effects. For instance, Basil (1996) found that people who identified with celebrities who endorsed healthy behaviors increased their own attitudes towards healthy behaviors. However, studies such as that conducted by Huesmann, Eron, Lefkowitz, and Walder (1984) have found an association between identifying with aggressive TV characters and acting aggressively. According to Glaser's theory, these studies would fall under differential identification, despite not explicitly utilizing this term.

The other construct to be examined in the present study is criminogenic thinking (also referred to as criminal thinking). Developed by Yochelson and Samenow (1976), this construct was developed to examine the cognitive reasons why offenders engage in criminal behaviors. Together, Yochelson and Samenow (1976) identified thinking errors they believed pervaded everything in a criminal's life and generalized them into patterns of criminogenic thinking. Walters (1990) later expanded the concept of criminogenic thinking to all individuals rather than only offenders, arguing that all people experience thinking errors that can lead to a broad range of maladaptive behaviors.

Recent research provides support that criminogenic thinking is applicable to nonoffenders. Of particular relevance to the present study, Mandracchia and Pendleton (2015) found an association between criminogenic thinking and risky behavior (e.g., criminal activity, high-risk sexual activity, academic dishonesty, etc.) in college students. Additionally, Riopka, Coupland, and Olver (2015) found a positive correlation between criminogenic thinking and antisocial behavior (e.g., criminal activity, reckless driving, being suspended from school, etc.) in college students. Criminogenic thinking has also been associated with spending time with criminals (Boduszek et al., 2013), which is in accordance with Sutherland's theory of differential association. However, no known research has examined the relationship between criminogenic thinking and identification with "outside" individuals (e.g., celebrities, fictional characters, etc.), let alone their 
subsequent effects on risk-taking behavior. Therefore, this study is novel because it seeks to expand upon previous research through the examination of differential identification as it relates to criminogenic thinking and risky behaviors.

Although these two constructs have received little attention in the risk-taking literature, they are important in that they have the potential to inform future research and interventions aimed at reducing risk-taking behaviors in emerging adults. Criminogenic thinking has been found to be a dynamic risk factor for problematic behaviors such as crime and other antisocial acts (Andrews \& Bona, 2016). From this perspective, clinicians working with risk-taking individuals can target these maladaptive thought patterns through interventions such as Cognitive Behavioral Therapy (CBT). In other words, addressing criminogenic thinking in treatment may potentially decrease risky behavior in emerging adults. As for differential identification, this theory can be utilized as a framework to better understand why emerging adults choose to engage in risktaking behaviors. For instance, individuals who strongly identify with either real or imagined negative influences (e.g., villains, criminals, etc.) may be more likely to engage in risky behaviors. From this perspective, future researchers and clinicians may be able to predict behavioral outcomes (like risk-taking behavior) through these identifications. However, it is important to note that this study is merely a preliminary evaluation of the relationship between these constructs, and much more work needs to be done in this area before these implications can be examined.

\subsection{Current Study}

One possible way to bridge the gap between these two constructs is to incorporate motivation as a factor for risk-taking. The Theory of Planned Behavior (TPB: Ajzen, $1985,1987,1991)$, for instance, is based on the premise that motivation (i.e., intent) is a direct precursor of behavior. In other words, the stronger the intention is to perform a certain behavior, the more likely the behavior will be performed. TPB has already been utilized to both explain and predict risky behaviors such as alcohol abuse, gambling, and reckless driving (Collins \& Carey, 2007; Lostutter, Holmes, \& Larimer, 2013; Parker, Manstead, Stradling, Reason, \& Baxter, 1992). Therefore, the aim of the proposed study is to examine the relationship between criminogenic thinking, differential identification, motivation to engage in risk-taking behavior, and actual engagement in risk-taking behavior among emerging adults. No known study examines these constructs together, but based on the literature it was hypothesized that motivation would moderate (1) the relationship between differential identification and risk-taking 
behavior and (2) the relationship between criminogenic thinking and differential identification.

\section{Method}

\subsection{Participants}

The sample for this study consisted of 309 emerging adults (i.e., 18-25 years old, M $=23.04, \mathrm{SD}=1.76$ ) who reside in the United States. Most participants were female ( $n=212,68.6 \%$ ). This is consistent with previous literature, which has found that MTurk samples are typically underrepresented by males (Ipeirotis, 2010; Paolacci et al., 2010). The overwhelming majority of participants identified as either Caucasian/ White $(n=200,64.7 \%)$, Asian/Asian American $(n=39,12.6 \%)$, or Hispanic/Latino(a) $(n=33,10.7 \%)$. In terms of criminal history, $86.4 \%(n=267)$ of participants reported having never committed a crime, and $94.5 \%(n=292)$ of participants reported having never been convicted of a crime.

\section{Materials}

Demographics form. A demographics form was created to ask participants' basic information such as age, race, and education status. Information specific to the study's constructs, such as criminal history, was also included in the form. For a full description of demographic information, please see Table 1.

Table 1. Participant Demographics

\begin{tabular}{|l|c|c|c|c|}
\hline & $\mathbf{N}$ & $\mathbf{\%}$ & Mean & SD \\
\hline Age & $\mathbf{3 0 9}$ & & $\mathbf{2 3 . 0 4}$ & $\mathbf{1 . 7 6}$ \\
\hline $18-21$ & 57 & 18.4 & & \\
\hline $22-25$ & 252 & $81.6 \%$ & & \\
\hline Gender & & & & \\
\hline Male & 94 & $30.4 \%$ & & \\
\hline Female & 212 & $68.6 \%$ & & \\
\hline Nonbinary & 3 & $0.9 \%$ & & \\
\hline Race/Ethnicity & & & & \\
\hline African American/Black & 24 & $7.8 \%$ & & \\
\hline Caucasian/White & 200 & $64.7 \%$ & & \\
\hline Hispanic/Latino(a) & 33 & $10.7 \%$ & & \\
\hline Asian/Asian American & 39 & $12.6 \%$ & & \\
\hline Native American/American Indian & 6 & $1.9 \%$ & & \\
\hline Middle Eastern & 1 & $0.3 \%$ & & \\
\hline Native Hawaiian/Pacific Islander & 1 & $0.3 \%$ & & \\
\hline Mixed race & 4 & $1.2 \%$ & & \\
\hline
\end{tabular}




\begin{tabular}{|l|c|c|l|l|}
\hline Highest Grade Level & & & & \\
\hline Advanced degree (MA, PhD, MD, etc.) & 19 & $6.1 \%$ & & \\
\hline College degree (AA, BA, BS, etc.) & 153 & $49.5 \%$ & & \\
\hline Some college, but no degree & 102 & $33.0 \%$ & & \\
\hline High school diploma or GED (12th grade) & 34 & $11.0 \%$ & & \\
\hline Grade school (8th grade) & 1 & $0.3 \%$ & & \\
\hline Marital Status & & & & \\
\hline Never married/single & 200 & $64.7 \%$ & & \\
\hline Married & 66 & $21.4 \%$ & & \\
\hline Partnered/common law & 37 & $12.0 \%$ & & \\
\hline Divorced & 4 & $1.3 \%$ & & \\
\hline Separated & 2 & $0.6 \%$ & & \\
\hline Have you ever committed a crime? & & & & \\
\hline No & 267 & $86.4 \%$ & & \\
\hline Yes & 42 & $13.6 \%$ & & \\
\hline Have you ever been convicted of a crime? & & & & \\
\hline No & 292 & $94.5 \%$ & & \\
\hline Yes & 17 & $5.5 \%$ & & \\
\hline Are you diagnosed with a mental disorder? & & & & \\
\hline No & 212 & $68.6 \%$ & & \\
\hline Yes & 97 & $31.4 \%$ & & \\
\hline $\begin{array}{l}\text { Are you receiving treatment for your mental } \\
\text { disorder? }\end{array}$ & & & & \\
\hline No & 226 & $73.1 \%$ & & \\
\hline Yes & $26.9 \%$ & & \\
\hline
\end{tabular}

Risk-Taking Behavior Measure (Mandracchia \& Pendleton, 2015). To measure actual risk-taking behavior, this measure, originally adapted from the Risk and Reckless Behavior Questionnaire (Bradley \& Wildman, 2002), consists of 25 risky behaviors in which emerging adults may be likely to engage in. Participants were asked to indicate the number of times they had engaged in each within the past six months. Examples of these behaviors include academic dishonesty, underage alcohol consumption, and unprotected sex.

Measure of Criminogenic Thinking Styles (MOCTS; Mandracchia, 2017). The MOCTS is a 70-item measure comprised of five scales: three subscales of criminogenic thinking (i.e., Control, Cognitive Immaturity, and Egocentrism), a Total Criminogenic Thinking scale, and an Inattentiveness scale. Control is defined as a need for power and control over oneself and others, as well as reduction or avoidance of fear about engaging in risk-taking behavior. Cognitive immaturity is defined as one's excessive 
use of cognitive heuristics (e.g., labeling, judging). Egocentrism is defined as one's emphasis of their own importance and uniqueness. The Control scale consists of 26 items, the Cognitive Immaturity scale consists of 28 items, and the Egocentrism scale consists of 11 items. Participants respond to items using a 5-point Likert scale ranging from 1 (Strongly Disagree) to 5 (Strongly Agree). The items from each subscale are totaled to create an overall score for each facet of criminogenic thinking. Higher scores indicate higher levels of criminogenic thinking. The Total Criminogenic Thinking scale is computed by totaling all three subscales into an overall score. The Inattentiveness scale consists of 5 items, each with one correct response - if participants respond correctly they receive a score of 0 for that item, and if they respond incorrectly they receive a score of 1 for that item. Higher scores indicate higher inattentiveness, and if participants scored above a 2 , they were excluded from the final analyses.

Motives for Risk-Taking Scale (MRT; Kloep, Güney, Çok, \& Simsek, 2009). The MRT consists of 26 items designed to measure three categories of motivation for risk-taking behavior, which are further broken down into two subcategories. These categories (and the corresponding subcategories) include: irresponsible behaviors (irresponsibility/achieving future goals and success), audience-controlled risk-taking behaviors (social desirability/ popularity seeking), and thrill-seeking behaviors (novelty and sensation seeking/hedonism). Each subscale consists of 6 items that participants respond to using a Likert scale that ranges from 1 (Disagree Totally) to 4 (Agree Totally). Participants respond to the statement "I sometimes take risks or do something dangerous because..." followed by a phrase related to one of the subscales of motivation. For example, "I sometimes take risks or do something dangerous because it is important for me to be popular" is one item from the popularity seeking subscale. The corresponding items from each subscale are totaled, with each subscale having its own total. Higher scores indicate higher motivation in that subscale.

Differential Identification Measure ${ }^{I}$. This measure was created for the purposes of this study and was designed in line with Glaser's (1956) definition of the construct: identifying with real or imaginary individuals who accept criminal behavior. Part 1 of the measure first asked participants to think of the top three people or groups of people in their life that have the most influence on them, which was adapted from Part A of the Measures of Criminal Attitudes and Associates (MCAA; Mills \& Kroner, 1999). Next, participants indicated the amount of time they spend interacting with each person/ group (0-2 hours, 3-4 hours, 5-6 hours, 7-8 hours, or over 8 hours). For each of the three people/groups in Part 1, the participant answered items about how much they 
identify with that person/group (i.e., an identification subscale) and then about that person/group's criminal activities (i.e., a criminality subscale). The identification subscale consists of 10 statements about the relationship between themselves and each person/group using a 5-point Likert scale ranging from 1 (Strongly Disagree) to 5 (Strongly Agree). Example statements include "This person/group is like me in many ways" and "I identify with this person/group". This part of the measure was adapted from the Player Identification Scale (Van Looy, Courtois, De Vocht, \& De Marez, 2012), which was originally created to measure players' identification to video game characters. For the final item of the identification subscale, participants were presented with the Inclusion of Other in the Self Scale (IOS; Aron, Aron, \& Smollan, 1992), a diagram $^{1}$ which consists of a series of two circles that increase from no overlap (1) to complete overlap (8), and were instructed to choose the one that best represents themselves in relation to each person/group. For the criminality subscale, participants answered five questions about each person/group's criminal behavior in the past year with either "Yes", "No", or "Don't Know", one example being "Did this person, or a person from this group, commit a crime?". For the final item of the criminality subscale, participants rated the overall criminality of each person/group using a scale of 1-10.

Part 2 of the measure again asked participants to think of the top three people or groups of people that have the most influence on them, but not actually part of their life (i.e., identification without actual association). In other words, people and groups that are not within the participant's social circle, yet have strongly impacted their personal development and behavior. Unlike Part 1, these individuals could be either real (e.g., a celebrity, sports team, etc.) or fictitious (e.g., a TV show cast, book character, etc.). Participants then answered the exact same questions for these people/groups as they did for Part 1. An identification subscale score and criminality subscale score is produced for each of the three individuals/groups in Part 1 as well as Part 2; for each individual/group, the identification and criminality subscale score was multiplied together to produce a score that represents the potential negative impact the individual/ group has on the respondent, in line with the theory of differential identification (i.e., the stronger a respondent identifies with an individual/group high in criminality, the stronger likelihood of negative impact on the respondent's behavior). For the analyses, these sets of scores were used to create two overall differential identification scores: one for Part 1 (with the resulting identification X criminality scores summed across all three individuals/groups in this section) and one for Part 2 (with resulting identification $\mathrm{X}$ criminality scores summed across all three individuals/groups in this section). 


\subsection{Procedure}

Participants were recruited via Amazon's Mechanical Turk (MTurk), a crowdsourcing platform that connects researchers and organizations to human participants. MTurk was created by Amazon in 2005 with the purpose of allowing individuals to hire workers to complete computer-based tasks for a monetary reward (Levay et al., 2016). In other words, workers from MTurk voluntarily sign up to participate in various projects that are posted online. The survey was posted in October 2018 and was made available for a period of two months. Participants completed the survey materials on Google Forms. Of the original 600 responses, only 309 were retained for the final analyses after excluding participants who were inattentive, outside the age range, and those who failed to report their age.

\section{Results}

\subsection{Data Screening and Preparation}

For the Differential Identification Measure, the internal consistencies of the identification and criminality subscales for each person/group in Part 1 and Part 2 ranged from .746 to 929 . Originally, the criminality subscales had much lower internal consistencies (e.g., Cronbach's alpha $=.329$ for the first person/group in Part 1). Upon further investigation, it was discovered that the last question (i.e., where participants rated the person/group's overall criminality) was weakly correlated $(r=<0.3)$ with the other questions. This is likely due to the fact that the item was based on participants' subjective rating of overall criminality, whereas the other items were based on participants' reports of objective criminal behaviors. To verify, the question was removed, and the internal consistencies of the criminality subscales significantly improved (i.e., ranged from .746 to .814$)$.

Before calculating the final scores, the diagram item on the identification subscale was rescaled from an 8-point scale to a 5-point scale to match the rest of the items. Additionally, the identification subscale (11 items) was prorated so that the scores would not outweigh the scores from the criminality subscale (5 items). The final scores for Part 1 and Part 2 were then calculated by multiplying the identification subscale by the criminality subscale for each person/group (i.e., 3 times for Part 1 and 3 times for Part 2) and adding the scores together to create an overall total score for Part 1 and Part 2. 


\subsection{Primary Analyses}

To evaluate the relationship between the predictor variables (i.e., criminogenic thinking, differential identification, and motivation) and the criterion variable (i.e., risk-taking behavior), a hierarchical multiple linear regression (HMLR) was conducted. In Block 1, criminogenic thinking, differential identification (Part 1 and Part 2, separately), and motivation were placed into the model. In Block 2, the three interaction terms (criminogenic thinking x motivation, differential identification (part 1) x motivation, and differential identification (part 2) x motivation) were added into the model. The means and standard deviations of the predictor and criterion variables are presented in Table 2.

Table 2. Correlations, Means, and Standard Deviations of Variables

\begin{tabular}{|c|c|c|c|c|c|}
\hline & RT & MOCTS & MRT & $\begin{array}{c}\text { DIFF ID } \\
\text { (P1) }\end{array}$ & $\begin{array}{c}\text { DIFF } \\
\text { ID (P2) }\end{array}$ \\
\hline $\begin{array}{ll}\text { RT } & \text { Pearson Correlation } \\
\text { Sig. (2-tailed) } & \\
\text { N } & \end{array}$ & $\begin{array}{c}1 \\
302\end{array}$ & $\begin{array}{l}.193 * * \\
.000 \\
302\end{array}$ & $\begin{array}{l}.174 * * \\
.001 \\
301\end{array}$ & $\begin{array}{l}.016 * * \\
.000 \\
302\end{array}$ & $\begin{array}{l}.041 * * \\
.000 \\
300\end{array}$ \\
\hline $\begin{array}{ll}\text { MOCTS Pearson Correlation } \\
\text { Sig. (2-tailed) } \\
\text { N }\end{array}$ & $\begin{array}{l}.193 * * \\
.000 \\
302\end{array}$ & $\begin{array}{c}1 \\
309\end{array}$ & $\begin{array}{l}. \mathbf{4 3 2} * * \\
.000 \\
308\end{array}$ & $\begin{array}{l}.208 * * \\
.000 \\
288\end{array}$ & $\begin{array}{l}.252 * * \\
.000 \\
282\end{array}$ \\
\hline $\begin{array}{l}\text { MRT Pearson Correlation } \\
\text { Sig. (2-tailed) } \\
\text { N }\end{array}$ & $\begin{array}{c}.174^{* *} \\
.001 \\
301\end{array}$ & $\begin{array}{l}. \mathbf{4 3 2} * * \\
.000 \\
308\end{array}$ & $\begin{array}{c}1 \\
308\end{array}$ & $\begin{array}{l}.164 \\
.002 \\
287\end{array}$ & $\begin{array}{l}.215 * * \\
.000 \\
281\end{array}$ \\
\hline $\begin{array}{l}\text { DIFF ID (P1) Pearson Correlation } \\
\text { Sig. (2-tailed) } \\
\text { N }\end{array}$ & $\begin{array}{l}.351 * * \\
.000 \\
302\end{array}$ & $\begin{array}{l}. \mathbf{2 0 8 * *} \\
.000 \\
288\end{array}$ & $\begin{array}{l}.164 \\
.002 \\
287\end{array}$ & $\begin{array}{c}1 \\
288\end{array}$ & $\begin{array}{l}.561 * * \\
.000 \\
266\end{array}$ \\
\hline $\begin{array}{l}\text { DIFF ID (P2) Pearson Correlation } \\
\text { Sig. (2-tailed) } \\
\text { N }\end{array}$ & $\begin{array}{l}. \mathbf{2 5 3} * * \\
.000 \\
300\end{array}$ & $\begin{array}{l}.252 * * \\
.000 \\
282\end{array}$ & $\begin{array}{c}\mathbf{. 2 1 5 * *} \\
.000 \\
281\end{array}$ & $\begin{array}{c}. \mathbf{5 6 1} 1^{* *} \\
.000 \\
266\end{array}$ & $\begin{array}{c}1 \\
282\end{array}$ \\
\hline MEAN & 9.19 & 174.85 & 55.52 & 11.07 & 21.73 \\
\hline STD. DEVIATION & 20.08 & 35.90 & 16.53 & 31.80 & 41.44 \\
\hline
\end{tabular}

Note. RT, Risk-Taking Behavior Measure; MOCTS, Measure of Criminal Thinking Styles; DIFF ID, Differential Identification Measure; MRT, Motives for Risk Taking Scale; Note. Boldface indicates statistical significance of $\mathrm{p}<.05 ; * *$ indicates a statistical significance of $\mathrm{p}<.001$.

Block 1 accounted for $14.5 \%$ of the variance in risk-taking behavior $(\Delta \mathrm{F}(4,295)=$ $12.539, p<.000)$. Differential identification part $1(\beta=.292, t(4)=24.477, p<.001)$ contributed significantly to the prediction of risk-taking behavior, such that identifying with close, deviant individuals was associated with increased risk-taking behavior. Block 2 only accounted for an additional $1 \%$ of the variance in risk-taking behavior $(\Delta \mathrm{F}(7,292)=7.683, p<.001)$. Aside from the discovery of a main effect between 
differential identification part 1 and risk-taking behavior $(\beta=.292, t(4)=4.477, p<$ $.001)$, no other variables were significant. Full results from the HMLR are presented in Table 3.

Table 3. Hierarchical Multiple Linear Regression Predicting Risk-Taking Behavior

\begin{tabular}{|c|c|c|c|c|c|}
\hline Predictor & $\Delta F(p)$ & $\Delta \mathbf{R}^{2}$ & b & $\beta$ & $t(p)$ \\
\hline $\begin{array}{l}\text { Block } 1 \\
\text { MOCTS } \\
\text { DIFF ID (P1) } \\
\text { DIFF ID (P2) } \\
\text { MRT }\end{array}$ & $12.539(<.001) * *$ & .145 & $\begin{array}{l}.048 \\
.184 \\
.024 \\
.095\end{array}$ & $\begin{array}{l}.085 \\
.292 \\
.050 \\
.078\end{array}$ & $\begin{array}{c}1.405(.161) \\
4.477(.000) * * \\
.761(.447) \\
1.296(.196)\end{array}$ \\
\hline $\begin{array}{l}\text { Block } 2 \\
\text { MOCTS } \\
\text { DIFF ID (P1) } \\
\text { DIFF ID (P2) } \\
\text { MRT } \\
\text { MOCTS x MRT } \\
\text { DIFF ID (P1) x MRT } \\
\text { DIFF ID (P2) x MRT }\end{array}$ & $1.177(<.319)$ & .010 & $\begin{array}{l}.002 \\
-.062 \\
.054 \\
-.060 \\
.001 \\
.004 \\
-.001\end{array}$ & $\begin{array}{l}.004 \\
-.098 \\
.112 \\
-.049 \\
.168 \\
.442 \\
-.118\end{array}$ & $\begin{array}{l}.022(.983) \\
-.437(.662) \\
.548(.584) \\
-.202(.840) \\
.470(.639) \\
1.767(.078) \\
-.490(.635)\end{array}$ \\
\hline
\end{tabular}

Note. MOCTS, Measure of Criminal Thinking Styles; DIFF ID, Differential Identification Measure; MRT, Motives for Risk Taking Scale; Note. Boldface indicates statistical significance of $\mathrm{p}<.05$; ** indicates a statistical significance of $\mathrm{p}<.001$.

\section{Discussion}

\subsection{Overview}

This study sought to examine the relationship between criminogenic thinking, differential identification, motivation, and risk-taking behavior in emerging adults. No known study has previously investigated these constructs together, let alone in the context of emerging adults. Inconsistent with the first hypothesis, motivation did not moderate the relationship between criminogenic thinking and risk-taking behavior. Interestingly, no main effect was found between criminogenic thinking and risk-taking behavior, which goes against previous literature (Mandracchia \& Pendleton, 2015; Riopka et al., 2015). No known research provides an explanation for these results, but perhaps something specific to this study affected the results. For instance, the sample may have lacked significant variation, as individuals from MTurk are not necessarily representative of the entire population. According to Vallas and Dietrich (2014), as many as 30\% of Americans have a criminal record, which is significantly higher than what participants reported (13.6\%). Additionally, the majority of the sample was female (68.8\%), which could have also influenced the findings. For instance, several studies have found gender differences in risk-taking, such that females tend to engage in less risky behaviors than 
males (Harris et al., 2006; Byrnes et al., 1999; Weber et al., 2002). This could be one potential explanation for the lack of significant findings. Another aspect of the study that may have affected the results is the way the constructs were measured. For instance, if the Risky Behavior Measure was not comprehensive enough in its scope of risky behaviors, the evaluation of the potential relationship between criminogenic thinking and motivation could have been impacted.

Inconsistent with the second hypothesis, motivation did not moderate the relationship between differential identification and risk-taking behavior. However, a main effect was found between differential identification part 1 and risk-taking behavior. As a reminder, part 1 involved individuals within a person's social circle, whereas part 2 involved individuals outside of a person's social circle. Therefore, participants who identified with deviant individuals with whom they actually associate with were more likely to engage in risky behavior-likewise, participants who identified with nondeviant individuals with whom they associate with were less likely to engage in risky behavior.

No main effect was found between differential identification part 2 and risk-taking behavior. One possible explanation to account for these differences is that people might be influenced differently by individuals they actually know and with whom they directly interact with versus individuals they do not. This may be due to the fact that "outside" individuals do not play as active of a role in an individual's life compared to close individuals. This is especially true for fictional characters - because they are fictitious, their actions are as well, which may have less of an impact than real people engaging in risky behaviors. Future research should be aimed towards examining the differences between identifying with real versus fictional individuals.

\subsection{Implications}

Given that this is the first known study of its kind, the following implications are preliminary in nature. It should be noted that further research in this area should be done before moving forward with these recommendations, including replication of this study and validation of the differential identification measure. Based on the information from this study, these results could potentially be useful in informing policies and practices about how to reduce risky behavior in emerging adults. For instance, the results of this study seem to support part 1 of Glaser's differential identification theory (i.e., our behavior is influenced by people we know and identify with). Therefore, educators and parents could potentially benefit from this by 
encouraging their children to identify with positive role models within their social circle. This could be achieved through mentoring programs such as Big Brother/Big Sister, Boys and Girls Club of America, and MENTOR. By participating in these programs, children may better avoid engaging in risky behaviors in the future. Dubois and Silverthorn (2005), for example, found that young adults in mentoring relationships were less likely to engage in risk-taking. Relatedly, this may also have important implications for mental health professionals. Arnett (2000), for instance, argued that identity formation issues remain prevalent during emerging adulthood. Therefore, young clients who identify with deviant individuals could explore in therapy why they identify with deviant individuals and can work towards finding positive, nondeviant individuals to identify with instead.

Part 2 of differential identification, on the other hand, was not found to be a significant predictor of risk-taking behavior. This result is surprising, given that previous literature has found an association between "outside" individuals and risk-taking behavior. For instance, a metanalysis of 35 research studies found that exposure to violent video games was associated with increased aggressive behavior and decreased prosocial behavior in children and young adults (Anderson \& Bushman, 2001). However, exposure to violence may only be one of many factors that link video games to aggression. Glaser, for example, might argue that one's identification with violent video game characters is a primary factor that leads to aggressive behavior. One study that seems to support this idea was conducted by Konijn, Nije Bijvank, and Bushman (2007), which found that boys who strongly identified with violent video game characters acted more aggressively than boys who did not. Therefore, despite the results of the present study, parents may benefit from remaining aware of the possible negative influence of media entertainment (e.g., movies, TV shows, social media, etc.) on children. Meanwhile, future research should continue to investigate the role of identification with "outside" individuals as it relates to problematic behaviors such as aggression and risk-taking.

\subsection{Limitations}

Data was obtained exclusively from self-report surveys, which rely on honesty and insight from participants. Due to the nature of this study, specifically in regard to criminal behavior, some participants may have provided inaccurate responses in order to present themselves in a more favorable light (i.e., social desirability bias). Another limitation is that participants were recruited using a convenience sampling approach, 
meaning they were chosen based on availability rather than randomly. Additionally, due to the cross-sectional and correlational nature of this study, temporal and causal conclusions cannot be drawn. Finally, the Differential Identification Measure was created for the purposes of this study (given there was not an existing measure of this construct), and therefore has no established validity.

\subsection{Future Directions}

From this study, there are multiple avenues of research that can be conducted. For instance, since this study appears to be the first of its kind, simply replicating the study would help determine the validity of the results. Replication could also be done with different populations to examine possible group differences. Adolescents would be especially informative, as they could provide more insight into the impact of identity development in emerging adults. Aside from replication, a longitudinal study would provide important information regarding the predictive ability of criminogenic thinking and differential identification on future outcomes. Finally, each construct could be examined further within the context of motivation to investigate their individual contribution to risk-taking behavior. Differential identification, in particular, needs to be researched more in depth.

\section{Conclusion}

Risk-taking behavior continues to be a pertinent issue in society, especially among emerging adults. The results of this study illustrate the complexities of risk-taking behavior and the many factors that contribute to this phenomenon. An individual's decision to engage in problematic behaviors may be attributed, at least in part, to social influences. More studies need to be conducted in this area to better understand the risk factors associated with risk-taking behavior in order to reduce its prevalence in the future.

Peer-review: Externally peer-reviewed.

Conflict of Interest: The authors have no conflict of interest to declare.

Grant Support: The authors declared that this study has received no financial support. 


\section{References/Kaynakça}

Ajzen, I. (1985). From intentions to actions: A theory of planned behavior. In J. Kuhl \& J. Beckmann (Eds.), Action-control: From cognition to behavior (pp.11-39). Heidelberg: Springer.

Ajzen, I. (1987). Attitudes, traits, and actions: Dispositional prediction of behavior in personality and social psychology. In L. Berkowitz (Ed.), Advances in experimental social psychology (Vol. 20, pp. 1-63). New York: Academic Press.

Ajzen, I. (1991). The theory of planned behavior. Organizational Behavior and Human Decision Processes, 50 , (179-211).

Anderson, C. A., \& Bushman, B. J. (2001). Effects of violent video games on aggressive behavior, aggressive cognitive, aggressive affect, physiological arousal, and prosocial behavior: A meta-analytic review of the scientific literature. Psychological Science, 12(5), 353-359.

Andrews, D. A., \& Bonta, J. (2016). The psychology of criminal conduct (6th ed.). Cincinnati, OH: Anderson Publishing.

Arnett, J. (2000). Emerging adulthood: A theory of development from the late teens through the twenties. American Psychologist, 55(5), 469-480.

Arnett, J. (2002). Developmental sources of crash risk in young drivers. Injury Prevention, 8, ii17-ii23.

Aron, A., Aron, E., \& Smollan, D. (1992). Inclusion of Other in the Self Scale and the structure of interpersonal closeness. Journal of Personality and Social Psychology, 63(4), 596-612.

Basil, M. (1996). Identification as a mediator of celebrity effects. Journal of Broadcasting \& Electronic Media, 40(4), 478-495.

Boduszek, D., Adamson, G., Shevlin, M., Hyland, P., \& Bourke, A. (2013). The role of criminal social identity in the relationship between criminal friends and criminal thinking style within a sample of recidivistic prisoners. Journal of Human Behavior in the Social Environment, 23(1), 14-28.

Bradley, G. \& Wildman, K. (2002). Psychosocial predictors of emerging adults' risk and reckless behaviors. Journal of Youth and Adolescence, 31(4), 253-265.

Byrnes, J. P., Miller, D. C., \& Schafer, W. D. (1999). Gender differences in risk taking: A meta-analysis. Psychological Bulletin, 125, 367-383.

Centers for Disease Control and Prevention. (2017). Sexually Transmitted Disease Surveillance 2016. Atlanta: U.S. Department of Health and Human Services. Retrieved from https://www.cdc.gov/std/stats16/CDC_2016_ STDS_Report-for508WebSep21_2017_1644.pdf

Collins, S. \& Carey, K. (2007). The theory of planned behavior as a model of heavy episodic drinking among college students. Psychology of Addictive Behaviors: Journal of the Society of Psychologists in Addictive Behaviors, 21(4), 498-507.

Dubois, D. L., \& Silverthorn, N. (2005). Natural mentoring relationships and adolescent health: Evidence from a national study. American Journal of Public Health, 95(3), 518-524.

Finer, L.B., \& Zolna, M.R. (2016). Declines in unintended pregnancy in the United States, 2008-2011. New England Journal of Medicine, 374(9), 843-852.

Gateway Foundation. (n.d.) Effects of drug abuse and addiction. Retrieved from https://recovergateway.org/ substance-abuse-resources/drug-addiction-effects/

Glaser, D. (1956). Criminality theories and behavioral images. American Journal of Sociology, 61(5), 433-444.

Halpern, C. T., Spriggs, A. L., Martin, S. L., \& Kupper, L. L. (2009). Patterns of intimate partner violence victimization from adolescence to young adulthood in a nationally representative sample. Journal of Adolescent Health, 45(5), 508-516.

Harris, C.R., Jenkins, M., \& Glaser, D. (2006). Gender differences in risk assessment: Why do women take fewer risks than men? Judgment and Decision Making, 1(1), 48-63. 
Hedegaard, H., Warner, M., \& Miniño, A.M. (2017). Drug overdose deaths in the United States, 1999-2016 (NCHS Data Brief No. 294). Hyattsville, MD: National Center for Health Statistics. Retrieved from https:// www.cdc.gov/nchs/data/databriefs/db294.pdf

Hooper, Komarraju, Weston, \& Dollinger (2007). Is plagiarism a forerunner of other deviance? Imagined futures of academically dishonest students. Ethics \& Behavior, 17(3), 323-336.

Huesmann, L., Eron, L., Lefkowitz, M., \& Walder, L. (1984). Stability of aggression over time and generations. Developmental Psychology, 20(6), 1120-1134.

Ipeirotis, P. G. (2010). Demographics of Mechanical Turk (CeDER Working Paper No. 10-01). New York University. Retrieved from http://www.ipeirotis.com/wp-content/uploads/2012/02/CeDER10-01.pdf

Kloep, M., Güney, N., Çok, F., \& Simsek, Ö.F. (2009). Motives for risk-taking in adolescence: A cross-cultural study. Journal of Adolescence, 32, 135-151.

Konijn, E. A., Nije Bijvank, M., \& Bushman, B.J. (2007). I wish I were a warrior: The role of wishful identification in the effects of violent video games on aggression in adolescent boys. Developmental Psychology, 43(4), 1038-1044.

Levay, K. E., Freese, J., \& Druckman, J. N. (2016). The demographic and political composition of Mechanical Turk samples. Sage Open, 6(1),1-17.

Lostutter, T., Holmes, J. K., \& Larimer, M. E. (2013). College student gambling: Etiology, consequences, and prevention strategies. In P. M. Miller (Ed.), Interventions for addiction: Comprehensive addictive behaviors and disorders, (pp. 883-892). San Diego, CA: Elsevier.

Mandracchia, J.T. (2017). Measure of Criminogenic Thinking Styles (MOCTS) manual. Unpublished manual and user guide.

Mandracchia, J. T. \& Pendleton, S. (2015). Understanding college students' problems: Dysfunctional thinking, mental health, and maladaptive behavior. Journal of College Student Retention: Research, Theory, \& Practice 17(2), 226-242.

McCabe, D. (2015). Cheating and honor: Lessons from a long-term research project. In Bretag, T. (Eds.), Handbook of academic integrity (pp. 1-9). Springer, Singapore.

Mills, J., \& Kroner, D., (1999). Measures of Criminal Attitudes and Associates User Guide. Kingston, Ontario, Canada: Author.

National Highway Traffic Safety Administration (2018). 2017 Alcohol-impaired driving traffic safety fact sheet (DOT HS No. 812630). Washington, D.C.: National Highway Traffic Safety Administration. Retrieved from https:/crashstats.nhtsa.dot.gov/Api/Public/ViewPublication/812630

Nelson, D. A., Springer, M. M., Nelson, L. J., \& Bean, N. H. (2008). Normative beliefs regarding aggression in emerging adulthood. Social Development, 17(3), 638-660.

Paolacci, G., Chandler, J., \& Ipeirotis, P. G. (2010). Running experiments on Amazon Mechanical Turk. Judgment and Decision Making, 5, 411-420.

Parker, D., Manstead, A., Stradling, S., Reason, J., \& Baxter, J. (1992). Intention to commit driving violations: An application of the theory of planned behavior. Journal of Applied Psychology, 77(1), 94-101.

Riopka, S., Coupland, R., \& Olver, M. (2015). Self-reported psychopathy and its association with criminal cognition and antisocial behavior in a sample of university undergraduates. Canadian Journal of Behavioural Science, 47(3), 216-225.

Stack, S. (1990). Divorce, suicide, and the mass media: An analysis of differential identification, 1948-1980. Journal of Marriage and Family, 52(2), 553-560.

Stratton, J. (1967). Differential identification and attitudes toward the law. Social Forces, 46(2), $256-262$.

Substance Abuse and Mental Health Services Administration. (2018). Key substance use and mental health indicators in the United States: Results from the 2017 National Survey on Drug Use and Health. (HHS Publication No. SMA 18-5068, NSDUH Series H-53). Rockville, MD: Center for Behavioral Health Statistics and Quality, Substance Abuse and Mental Health Services Administration. Retrieved from https://www. samhsa.gov/data/sites/default/files/cbhsq-reports/NSDUHFFR2017/NSDUHFFR2017.pdf 
Trivedi, N., Haynie, D., Bible, J., Liu, D., \& Simons-Morton, B. (2017). Cell phone use while driving: Prospective association with emerging adult use. Accident Analysis \& Prevention, 106, 450-455.

Vallas, R., \& Dietrich, S. (2014). One strike and you're out: How we can eliminate barriers to economic security and mobility for people with criminal records. Washington D.C.: Center for American Progress. Retrieved from https://cdn.americanprogress.org/wp-content/uploads/2014/12/VallasCriminalRecordsReport.pdf

Van Looy, J., Courtois, C., De Vocht, M., \& De Marez, L. (2012). Player identification in online games: Validation of a scale for measuring identification in MMOGs. Media Psychology, 15(2), 197-221.

Walters, G. D. (1990). The criminal lifestyle: Patterns of serious criminal conduct. Newbury Park, CA: Sage.

Weber, E. U., Blais, A., \& Betz, E. N. (2002). A domain specific risk-attitude scale: Measuring risk perceptions and risk behaviors. Journal of Behavioral Decision Making, 15, 263-290.

Yochelson, S., \& Samenow, S. (1976). The criminal personality (vol. 1): A profile for change. New York, NY: Jason Aronson. 